\section{Expropiados apropiados del espacio público. Aportes para el análisis de la vinculación entre organizaciones del capital y el Estado}

Expropriated and appropriated of the public space. Contributions to analyze the link between capital organizations and the State

\section{Margarita MoschenI ${ }^{\star}$}

\section{Resumen}

En este artículo la discusión gira en torno a la vinculación entre las organizaciones no gubernamentales que representan a distintas fracciones del capital con el Estado y sus políticas públicas. Se supone que las

Consejo Nacional de Investigaciones Científicas y Tecnológicas (CONICET) - Universidad Nacional de San Juan, Argentina. Correo electrónico: margarita.moscheni@gmail.com organizaciones integradas por agentes con mayor nivel de capitalización son las que tendrán también mayor acceso a los recursos públicos e influencia en el territorio. El Estado toma posición frente a aquellas cuestiones que son socialmente relevantes y es objetivo de este trabajo desentrañar dicha dinámica, respondiendo a los siguientes interrogantes: ¿cuál es el vínculo entre las organizaciones y el territorio?, ¿qué influencia ejercen en sus transformaciones?, ¿qué factores son importantes en el ejercicio de la territorialidad?, ¿cómo es la vinculación entre las organizaciones sectoriales y el Estado?, ¿qué características tienen las organizaciones con mayor incidencia en él?, ¿la cantidad de miembros es importante?, ¿los tipos de intervención estatales son diferentes según el tamaño de éstas? Como estrategia metodológica se utiliza el estudio de caso, tomando como unidades de análisis las organizaciones del sector vitivinícola de San Juan.

Palabras clave: organizaciones, Estado, políticas estatales, territorio.

\section{Abstract}

In this article the discussion revolves around the link between non-governmental organizations representing different fractions of capital with the State and public policies. It is assumed that organizations with subjects with greater power will better access public resources and influence in the territory. The State takes position on those issues which are socially relevant. The objective of this work is to unravel this dynamic, responding the following questions: what is the link between organizations and the territory?, what exerts influence in their transformations?, 
what are the important factors in the exercise of territoriality?, what is the link between sectorial organizations and the State?, what are the characteristics of the organizations more involved in it?, is the amount of members important?, does technology affect empowering organizations?, what kind of strategies are developed to achieve this?, are the types of State intervention different depending on the size of these? As methodological strategy, case study is used, taking as units of analysis wine sector organizations operating in the Province of San Juan today.

Key words: organizations, State, State policies, territory.

\section{Introducción}

Las organizaciones son parte de un entramado de relaciones de fuerza en un determinado territorio. Cada una se define por sus luchas, intereses ideológicos, estrategias y características de los miembros que las integran, entre otras cosas. En el logro de sus objetivos, tejen alianzas o se enfrentan en procesos conflictivos con otros agentes de poder, y entre ellos el Estado es clave en ese proceso. Las políticas estatales siguen una trayectoria que avanza a partir de sucesivas tomas de posición de los agentes privados y del Estado, sea por acción u omisión. Los agentes privados se agrupan en organizaciones civiles $y$, a través de ellas, las distintas fracciones del capital despliegan sus acciones y se apropian, o quedan excluidos, del espacio público.

En este trabajo se propone una mirada, descriptiva y analítica a la vez, de las organizaciones que representan a cada fracción histórica de la vitivinicultura en San Juan y su vinculación con el poder político, recogiendo las principales características, su composición y el entramado de las principales relaciones de fuerza que configuran sus avances y retrocesos.

En la primera sección se describen las cuestiones teóricas y metodológicas que orientan este estudio. En la segunda sección se describen los principales indicadores de la actividad vitivinícola a nivel nacional y provincial. En la tercera sección se describen las organizaciones, composición y principales características. Por último, se da cuenta del desarrollo y las conclusiones a las que se arriba.

\section{Algunas cuestiones conceptuales}

Las políticas estatales atraviesan un largo y complejo ciclo desde la problematización de la "cuestión" hasta su resolución (Oszlak y O’Donnell 1976: 8). Durante ese proceso se conforma un entramado de actores cuya toma de posición frente a la cuestión va variando. Los agentes del sector capital, los medios de comunicación, los trabajadores y los ciudadanos inciden en las políticas estatales a través de su participación en las organizaciones de la sociedad civil. Éstas pueden influir directamente en los productos del Estado a través de la imposición de algún tema en la agenda, la negociación de alguna propuesta, su aprobación, rechazo y difusión a la comunidad, movilizando a los diferentes actores públicos, e, indirectamente, pueden incidir en la modificación del territorio.

Para Madoery (2009), la heterogeneidad de las organizaciones que representan a la fracción del capital constituye un importante factor de 
dispersión en todo el proceso de las políticas estatales, delineando "un terreno fértil para el despliegue de lógicas conflictivas entre actores privados y que somete a los actores públicos a permanentes búsquedas de equilibrios que no siempre se alcanzan" (p. 90). En este trabajo las distintas fracciones del capital son miradas según el grado de integración de los agentes del capital que componen cada organización.

La integración se refiere a la capacidad de operar en uno o más eslabones de la cadena productiva. Si el agente interviene en un solo eslabón se dice que no está integrado, si opera en dos o más se denomina agente integrado. A mayor tamaño, habrá un mayor grado de integración y el agente tendrá mayor poder de captación del ingreso generado en el circuito productivo al que pertenece. Ese poder se traducirá entonces en la posibilidad de configurar las condiciones productivas y comerciales del bien generado. Se supone que el poder de un agente y su capacidad de imposición sobre el resto de los agentes en una cadena están asociados a la capacidad de vinculación de la organización sectorial a la que pertenecen con el Estado. Es probable que organizaciones cuyos miembros tengan mayores y mejores recursos, tengan también mayor capacidad de apropiación de los recursos públicos.

Según Schlemenson, "la organización constituye un sistema socio-técnico integrado, deliberadamente constituido para la realización de un proyecto concreto, tendiente a la satisfacción de necesidades de sus miembros y de una población o audiencia externa, que le otorga sentido. Está inserta en un contexto socioeconómico y político con el cual guarda relaciones de intercambio y de mutua determinación" (1993: 52). La dinámica de las organizaciones encierran para sí y entre sí mecanismos de negociación, poder y dominación, en tanto son instituciones que forman parte de las relaciones de poder en una sociedad determinada. En relación con esto, Schelmeson identifica al interior de la organización al "sistema político", como los grupos de poder que funcionan en forma paralela a la autoridad misma de la organización, y que despliegan diferentes acciones explícitas o implícitas de presión, influencia y conformación de alianzas en torno al logro de sus intereses. En este sentido, toda organización involucra una determinada estructura de relaciones de fuerza, que dejan en evidencia la participación y la búsqueda de poder, tanto interno como externo, mediada por una negociación constante sobre la homogeneización del discurso -incluyendo valores y normas-, y por las direcciones jerárquicas.

En cuanto a lo que sucede en el ámbito exterior, la organización mantiene una relación de retroalimentación constante con el medio en el que está inserta. El "contexto" supone diferentes aspectos que pueden amenazar la continuidad de su existencia, de sus fines tradicionales o iniciales, sus funciones, su estructura, miembros, etc.

Respecto a los recursos, una organización puede contar con bienes materiales (infraestructura) o recursos simbólicos, como las normas, las declaraciones de principios (Schvarstein 1992), el prestigio, la "influencia en la constitución de la agenda pública, reconocimiento como miembro de la sociedad civil local, poder para definir las reglas de juego para la participación e influir en la constitución del campo político" (Moscovich 2008: 22). La forma más concreta 
de incidencia en dicho campo es mirando al "Estado en movimiento" (Thwaites Rey 1999: 15), a través de las políticas estatales, definidas como un "conjunto de acciones y omisiones que manifiestan una determinada modalidad de intervención del Estado en relación a una cuestión que concita la atención, interés o movilización de otros actores de la sociedad civil” (Oszlak y O’Donnell 1976: 21).

Como no todos los temas entran en agenda y se convierten en una política estatal, Oszlak y O'Donnell afirman que son "socialmente problematizadas" sólo aquellas cuestiones que "ciertas clases, fracciones de clases, organizaciones, grupos, o incluso individuos estratégicamente situados creen que puede y debe hacerse algo a su respecto y están en condiciones de promocionar la incorporación a la agenda de problemas socialmente vigentes" (1976: 21). En el transcurso de la resolución de esta cuestión problematizada se forma un entretejido de concertaciones, alianzas, consensos, compromisos, acuerdos y conflictos, fundamentalmente porque una política siempre implica recursos de distintos tipos. "Cada política sería el producto de la compleja interacción de personas y organizaciones. Cada uno de esos actores transporta una cierta definición del problema a abordar, una cierta imagen de la realidad sobre la que se quiere intervenir" (Subirats y Gomá 1998: 25).

De manera más operativa, Inés GonzálezBombal (2003: 10) sistematiza la forma de participación de las organizaciones de la sociedad civil en el proceso de políticas estatales, de la siguiente manera:

- incidencia directa sobre legisladores o tomadores de decisión;
- incidencia indirecta a través de campañas de movilización social;

- formación de alianzas para la promoción de agendas específicas;

- participación en consejos de planeación o concertación de políticas nacionales o municipales de carácter general o sectorial;

- influencia en las propuestas de candidatos o de partidos políticos de la ciudadanía, y;

- desarrollo y difusión de investigaciones en temas sociales relevantes.

El Estado, integrado en sus distintos niveles por funcionarios públicos que representan determinadas relaciones de fuerza, articula acciones de inclusión o exclusión de los actores privados, constituidos o no en organizaciones sectoriales, que representan sus intereses de fracción, conformando así una arena pública-privada que da lugar a resistencias o a nuevas transformaciones territoriales. El territorio es definido como una configuración histórica y espacial de las relaciones de poder, producto de una formación social históricamente determinada, en otras palabras, de vinculaciones sociales y de la actividad económica que lo estructura, además de los hábitos y la cultura que lo identifican a través de la historia. Para Manzanal, el territorio es el "espacio donde se manifiestan y dirimen los conflictos económicos, sociales, políticos y culturales, donde se lucha por la conquista de los respectivos intereses y donde se disputa el poder político y económico" (2006: 25). De este modo, el territorio se analiza como espacio de poder que se configura a partir de las relaciones entre agentes que se inscriben en el marco de un particular proceso de reproducción social. En este sentido, se entiende por territorialidad el "intento por parte de un individuo o grupo de afectar, influenciar, o controlar personas, fenómenos y relaciones, a través de la delimitación y el establecimiento de un control 
sobre un área geográfica, es decir, el territorio" (Arqueros 2007: 137).

Este trabajo se propone examinar cómo las organizaciones inciden en las políticas públicas $y$, a su vez, indagar cuál es la incidencia del Estado en las organizaciones sectoriales, comprendiendo el territorio como el producto de la articulación de relaciones de fuerza, tanto públicas como privadas, y del ejercicio de ciertas territorialidades.

\section{Metodología}

Se trata de un estudio de tipo cualitativo inscrito dentro del esquema del paradigma interpretativo, que se desarrolla en el marco de una investigación descriptivo-analítica financiada por CONICET mediante una beca posdoctoral. La unidad de análisis son las organizaciones vinculadas a la cadena vitivinícola en la provincia de San Juan, Argentina ${ }^{1}$. La estrategia usada es el estudio de caso, y se eligió a las organizaciones del sector vitivinícola dado que es la actividad agroindustrial histórica más importante en la estructura productiva de la provincia. Se trabajó con una muestra no probabilística intencional o dirigida, en una primera etapa con la estrategia bola de nieve, combinando estrategias de muestreo de intensidad con expertos, completando con casos confirmadores y desconfirmadores. En cuanto a las técnicas de

La Argentina es un Estado nacional con un sistema federal de gobierno, cuyo poder se distribuye entre el gobierno federal y los gobiernos provinciales. Posee 23 provincias y la Ciudad Autónoma de Buenos Aires (CABA). Cada provincia tiene carácter de Estado subnacional, está gobernada por un gobernador, y se sub-divide políticamente en su interior en gobiernos municipales. Cada Municipio o Estado local está dirigido por un intendente. La provincia de San Juan está subdividida en 23 municipios, cada uno con su respectivo intendente municipal. recolección, se utilizaron para la obtención de datos primarios las entrevistas en profundidad, y para la obtención de datos secundarios se llevó a cabo la observación de documentos. Se realizaron 20 entrevistas a dirigentes de las organizaciones sociales más importantes en San Juan y 7 a funcionarios públicos.

\section{La importancia de la vitivinicultura y sus transformaciones en San Juan}

La vitivinicultura en Argentina comprende un total de 223.580 hectáreas implantadas y 25.372 viñedos en el 2013, de los cuales el $21,30 \%$ y el $21 \%$, respectivamente, corresponden a San Juan, segunda provincia productora de vid a nivel nacional. En este provincia la vitivinicultura estructuró históricamente el modelo agroindustrial, $\mathrm{y}$, hasta mediados del 2000, la actividad tipificó las principales relaciones socioeconómicas en el territorio. Las organizaciones productivas más antiguas y numerosas e, incluso, la mayor cantidad de sindicatos pertenecen al sector. Sin embargo, a partir de la década del 90 , en el intento por adaptarse al nuevo patrón competitivo global, la vitivinicultura provincial atraviesa por una serie de transformaciones productivas. En primer término es preciso mencionar la diversificación vitícola como uno de los cambios más importantes, pasando de una estructura tradicional, especializada en la producción de uvas y vinos comunes a granel, hacia una diversificación de la producción de uva para otros destinos, como lo son la uva en fresco, la pasa y los vinos finos. Según datos del Instituto Nacional Vitivinícola (INV), en el 2013 el $72 \%$ de la superficie implantada tuvo como destino variedades para vinificar, registrando una caída del $20 \%$ respecto a 1990 , año en 
que comprendía el $91 \%$ del total. Esa caída fue compensada con el crecimiento de uva para mesa, que mientras en 1990 representaba el 4\% del total, en 2013 crecía a un 21\%. A su vez, se registró un incremento positivo entre 1990 y 2013, que incluyó más de 6.000 hás. para el cultivo de variedades de alta calidad enológica, 8.200 para consumo en fresco y 900 para pasas.

Una segunda transformación territorial se refiere al crecimiento de la superficie en paralelo a la disminución de viñedos. Según datos del INV, respecto a 1990, la superficie implantada con vid en la Argentina creció en el 2013 en 13.209 hás. Así, mientras que en 1990 se registraron 210.371 hás., en el 2013 esa cifra ascendió a 223.580 hás. Correlativamente, en San Juan la superficie vitivinícola se incrementó en 1.483 hás., pasando de 46.150 en 1990 a 47.633 en el 2013. Al contrario del comportamiento observado en la superficie implantada, la cantidad de viñedos tuvo una tendencia negativa. En el 2013 San Juan registró 5.332, mientras que en 1990 tenía 9.037, es decir, disminuyó más de la mitad del total actual (3.707 viñedos). A nivel nacional se perdieron 11.030. Esto indica la desaparición de agentes en el sector primario que son absorbidos, marginados o directamente excluidos del circuito productivo. Los viñedos que más se perdieron fueron los más pequeños, de entre
0,1 y 25 hás., pasando de comprender el $97 \%$ en 1990 al $92 \%$ en el 2009 del total de viñedos en San Juan. La superficie ocupada también cayó: mientras que esta franja ocupaba una superficie del 73\% en 1990, en 2009 contaba con un $44 \%$. De manera inversa, los viñedos de entre 25,01 y más de 100 hás. pasaron de ocupar el $27 \%$ de la superficie en 1990 , a un $66 \%$ en el 2009, registrándose un crecimiento del tamaño promedio de las unidades productivas de los agentes más grandes.

Una tercera transformación se refiere a la reducción en la producción de uva para vinificar y en la elaboración de vinos, y al crecimiento del mosto. Según el INV, entre 1994 y 2014 dejaron de producirse 1.107.684 quintales métricos destinados a vino, y 2.189.951 hectolitros de vinos en San Juan. Respecto al mosto, según el INV, mientras que en el 2001 había en San Juan 461 fábricas con capacidad para 479.115 hectolitros, en el 2009 esas cifras aumentan a 497 fábricas y 571.504 hectolitros, es decir, en ocho años hay en San Juan 36 fábricas de mosto más. El mosto llegó a superar, en algunos años, más de la mitad de la producción en el rubro vitivinícola (particularmente en los años 2007/8 y 2011/12/13), y se reconoce como el bien exportable del que más dólares se obtienen por exportaciones en la cadena de la vid, tal como lo muestra el siguiente cuadro: 
Tabla 1. Exportaciones vitícolas. San Juan, Argentina. 1997-2008. Valor FOBB en miles de dólares

\begin{tabular}{|l|c|c|c|c|c|c|c|c|c|c|c|c|}
\hline \multicolumn{1}{|c|}{ Años } & 1997 & 1998 & 1999 & 2000 & 2001 & 2002 & 2003 & 2004 & 2005 & 2006 & 2007 & 2008 \\
\hline Total exportaciones & 134.170 & 138.801 & 139.627 & 157.400 & 137.141 & 140.397 & 146.635 & 206.583 & 274.299 & 675.001 & 742.113 & 981.840 \\
\hline Uvas frescas & 2.227 & 7.903 & 14.682 & 38.347 & 32.870 & 28.621 & 28.907 & 35.755 & 41.679 & 63.193 & 54.077 & 77.288 \\
\hline Pasas de uva & 9.957 & 9.836 & 13.171 & 9.644 & 6.722 & 11.240 & 8.149 & 19.682 & 25.280 & 22.704 & 34.330 & 38.341 \\
\hline Vino & 15.658 & 18.8266 & 16.346 & 13.141 & 9.704 & 8.128 & 11.074 & 15.215 & 23.903 & 33.727 & 43.775 & 57.405 \\
\hline Mostos & 29.650 & 13.100 & 16.095 & 13.353 & 9.006 & 12.375 & 18.489 & 34.357 & 52.494 & 53.599 & 73.999 & 103.182 \\
\hline $\begin{array}{l}\text { Total exportaciones } \\
\text { vitivinícolas }\end{array}$ & 57.493 & 49.666 & 60.296 & 74.487 & 58.303 & 60.365 & 66.621 & 105.010 & 143.358 & 173.225 & 206.183 & 276.217 \\
\hline
\end{tabular}

Fuente: IIEE en base de datos procesados por INDEC.

Según el Observatorio Vitivinícola Argentino (OVA), de los 719 establecimientos vitivinícolas en el país, el $62 \%$, corresponde a empresas con perfil de mercado interno, mientras que el $38 \%$ tiene un claro perfil exportador. Sin embargo, San Juan, a pesar de ser la segunda provincia productora de uvas y vinos y dedicarse históricamente a su producción, quedó relegada en las ventas comerciales. Según el mismo informe, sólo el $25 \%$ de sus establecimientos destina la mayor parte de su producción al comercio externo. Junto con ello, en el orden de las exportaciones, las bodegas de Argentina no cuentan con las ventajas de desgravaciones arancelarias que tienen las de otros países de la región. Al ser miembro del MERCOSUR, las bodegas tienen prohibido vender sus productos a granel, y San Juan es una provincia, en su mayoría, de capitales pequeños que venden fundamentalmente a granel$^{2}$, ya que el fraccionamiento implica

San Juan se caracteriza por tener una baja participación en el mercado fraccionador, ya que comprende sólo el $10 \%$ de fraccionamiento total de Argentina. importantes inversiones ${ }^{3}$. A ello se suma que el fraccionamiento en la provincia se concentra principalmente en nichos con niveles bajos en términos de calidad, rentabilidad y precio. El multilaminado o comúnmente conocido como tetra-brik, envases con vinos sin denominación varietal que se comercializan a precios relativamente bajos, comprende el $72 \%$ de las ventas fraccionadas -en el 2000 comprendía un $74 \%-$.

Por último, es importante hacer referencia a la modificación de la matriz socio-productiva en el sector y en la provincia. Nuevos agentes se incorporan al circuito productivo territorial, con una variada composición del capital: algunas empresas son absorbidas por capitales extranjeros, otras pertenecen a grupos extralocales pero de capitales nacionales, y otros persisten en agentes locales.

En el 2012 incorporar una línea de embotellado en una bodega sanjuanina superaba los 300 mil euros, por lo que el volumen de producción y las ganancias deben ser significativos para que se justifique hacer una inversión de este tipo. 
Entre los primeros se encuentra el caso de la bodega Grafigna, comprada en 2005 por Pernord Ricard, de origen francés; Callia, comprada en el 2003 por Sallentein, de origen holandés, y; Expofurt en la cadena de la uva en fresco, comprada en 1993 por el grupo italiano Bocchi, adquirida en el 2010 por el grupo belga Univeg, y vendida luego a un fondo común de inversiones.

Entre los segundos está Peñaflor, conocida tradicionalmente como Pulenta, que entre 1997 y 2002 es adquirida por el fondo de inversión estadounidense Donaldson, Lufkin \& Jenrette (DL \&J), y en el 2010 es comprada por los capitales nacionales Bemberg Inversora (Quilmes). En este grupo se puede mencionar también a FECOVITA, originada en la vieja estructura de la estatal Gioll ${ }^{4}$ y RPB BAGGIO, cuyos capitales son de la provincia de Entre Ríos. En la cadena del mosto, a las mencionadas Peñaflor y FECOVITA se suma ENAV, de capitales nacionales pertenecientes a Vincentin SAIC (Algodonera Avellaneda). Por último, se destaca el origen plenamente local de los agentes líderes en la cadena de la pasa, entre ellos encontramos a Sánchez-Sánchez, Meló, Cassab Ahún, Moya, Alves y Almeyda (Lusitano), Agroexport y Frutandina.

Como parte de las transformaciones territoriales no puede dejar de mencionarse la incorporación a la matriz productiva de un grupo nuevo de agentes en el sector, todos de capitales locales, de tamaño pequeño dentro de la cadena del vino, pero con integración superior compleja. Por un lado, están las

Antigua bodega estatal administrada por el gobierno de Mendoza, primera provincia productora de bienes vitícolas en la Argentina. bodegas boutique, entre las que se encuentran Aguma (2004), Merced del Estero (2004), Casa Montes (2001), Augusto Pulenta (1997), Sierras Azules (2004), y Cerro Andino (2001). Por otro lado, están pequeñas bodegas pertenecientes a capitales originados en otros sectores económicos de la provincia, de la mano de profesionales independientes o la minería, construcción o servicios. Entre éstos se hallan: San Juan de la Frontera (adquirida en 2002 por Menín Construcciones), la mencionada bodega boutique Casa Montes (proyecto nuevo iniciado por Francisco Montes de Diario de Cuyo), Esperanza de los Andes (iniciado en el 2001 por Ferrer Marmolería), Las Marianas (iniciada en el 2001 por la Flia. Batistella), Marqués del Ponte (iniciada por Autotransportes San Juan), Fraccionadora San Juan (comprada a Cordero por el Grupo San Ramón en el 2003 a la Flia. Cordero).

Son agentes que tienen un claro perfil diferenciado, relativamente pequeños, sus ventas comerciales externas no superan el $20 \%$ del proyecto, sus productos tienen una alta calidad enológica, y en la mayoría de los casos son proyectos de inversión nuevos con una importante incidencia en el desarrollo del territorio. En general, al ser externos a la industria tradicional, tienen una visión limitada del sector como cluster, incurriendo en prácticas individualistas, limitaciones para la definición del negocio, para el establecimiento de estrategias de marketing, de conservación del vino, comercialización y logística.

Como contracara de este territorio que logra adaptarse a las nuevas pautas de competitividad, se asiste a una tendencia estructural: expulsión o subordinación, subsunción y descapitalización de los 
pequeños y medianos agentes tradicionales, con dificultades importantes para integrarse a la cadena o reconvertirse hacia cadenas de mayor valor como la de la uva de mesa. La fracción más pequeña de productores vitícolas tradicionales no integrados quedó marginada, tanto de los recursos materiales como de los simbólicos. En efecto, los productores no sólo quedan al borde del nuevo modelo productivo y comercial, sino que son excluidos en la formalidad de los espacios de producción del discurso, de modo tal que no ocupan ningún lugar privilegiado en los ámbitos de decisión sobre las políticas vitivinícolas. En términos productivos y comerciales, los agentes no integrados o de integración simple se encuentran subsumidos o subordinados al gran capital, que se vale del mercado, los precios, la financiación y los contratos para mantener una relación de dependencia y valorizar su capital. Los recursos financieros, técnicos, físicos, educativos y sociales de los viñateros, sus capacidades de incidir en las políticas estatales y su organización social, los coloca en una posición y función de disparidad y asimetría al momento de comprar insumos, producir o vender sus productos.

\section{Las organizaciones vitivinícolas en San Juan}

\subsection{Organizaciones que representan a agentes no integrados}

La matriz social que integra el circuito productivo es diversa y numerosa. Los viñateros no integrados están organizados en la Federación de Viñateros de San Juan (FVSJ), la Asociación de Viñateros Independientes (AVI), y la Cámara de Productores Vitícolas (CAPROVIT).

\subsubsection{Federación de Viñateros de San Juan (FVSJ)}

La FVSJ fue creada en 1954, y originalmente tuvo como objetivo la unión de los productores no integrados para defender el precio de la uva y el vino, controlado por los grandes grupos económicos. En sus orígenes tuvo un importante poder de movilización (fue la que mayor cantidad de miembros tuvo, registrando alrededor de 4000 socios en 1976). Sin embargo, dicha fortaleza no pudo a lo largo de los años ser traducida en cambios estructurales que modificaran realmente la situación del pequeño viñatero, ésta fue y es su limitación más importante. Su principal aliado es la Asociación de Viñateros Independientes, y el adversario histórico es la fracción de los industriales bodegueros.

Respecto a los espacios de participación oficial, la Federación de Viñateros: es miembro del Consejo Regional Cuyo del Instituto Nacional de Tecnología Agropecuaria (INTA); integra el Consejo Asesor Técnico del Instituto Nacional Vitivinícola (INV); integra la mesa directiva en la Confederación General Económica de la República Argentina, y; es miembro paritario por San Juan en los acuerdos de los salarios de los obreros de viña y del precio del tacho de uva ante el Ministerio de Trabajo, Empleo y Seguridad Social de la Nación.

\subsubsection{Asociación de Viñateros Independientes (AVI)}

Se crea en 1965, en un contexto de crisis por excedente de vinos, concentración y surgimiento de grupos monopólicos en la actividad. Antes se llamaba Unión Federativa de Viñateros y Productores Agrícolas (UFEVIPA), y 
por su discurso de izquierda, sus actividades y miembros fueron reprimidos y su capacidad de expresión restringida a partir de $1976^{5}$, como buena parte de la sociedad argentina. Por la misma razón, recién obtuvo la personería jurídica al iniciarse la democracia, época en la que cambió su nombre a Asociación de Viñateros Independientes.

Actualmente tiene alrededor de 500 miembros. Es el grupo más combativo con una posición radicalmente opositora al gobierno provincial, y son denominados por la prensa y el resto de los agentes como "los viñateros rebeldes". No ocupan espacios oficiales de importancia, no son miembros paritarios, ni están reconocidos en las agencias de gobierno provincial.

\subsubsection{Cámara de Productores Vitivinícolas (CAPROVIT)}

Es la única que pertenece al ala oficialista y es la más nueva en la matriz social. Cuenta con una importante legitimidad política, aunque su base de representatividad es intrascendente. Se creó en el 2004, a partir de la exclusión de las dos organizaciones anteriores en el Plan Estratégico Vitivinícola (PEVI), principal política pública vitivinícola en Argentina.

\subsection{Organizaciones que representan a agentes integrados}

En la cadena del vino, los bodegueros a granel y elaboradores de mosto sulfitado se agrupan en la Cámara Vitivinícola de San Juan, y los

En ese año se produjo un golpe de Estado que depuso a la presidente María Estela Martínez de Perón, imponiéndose una junta militar liderada por Videla, Massera y Agosti. fraccionadores en la Cámara de Bodegueros. Los fabricantes de mosto están representados por la Cámara Argentina de Fabricantes y Exportadores de Mosto, y los de pasas por la Cámara de Pasas de Uva y Afines de San Juan y la Cámara de Comercio Exterior de San Juan. Por último, la uva en fresco no tiene representación sectorial exclusiva, no hay una cámara de uva en fresco en San Juan. Algunos de los agentes participan de la Cámara de Comercio Exterior, lo que se explica porque la mayor parte de esta producción es para exportación.

\subsubsection{Cámara Vitivinícola de San Juan}

Fue creada en 1939 como Sociedad de Bodegueros Trasladistas de San Juan y en 1964 reforma sus estatutos y comienza a llamarse Cámara Vitivinícola de San Juan. En ella seagrupan 92 bodegas a granel, que son en general las de más larga data en la provincia. Estas bodegas se vinculan hacia adelante con los agentes fraccionadores y hacia atrás con los productores no integrados que elaboran a maquila.

\subsubsection{Cámara de Bodegueros de San Juan}

Es la más antigua en la provincia, creada en 1934. Sus miembros son gerentes o dueños de las más grandes bodegas del territorio y su dirección está conformada por un gerente. Todos los agentes que la conforman tienen una integración superior compleja y/o conforman el núcleo de acumulación del circuito $^{6}$. Su

El núcleo de acumulación está integrado por agentes que, en virtud de los recursos que disponen, están en condiciones de imponer las características productivas y comerciales de un determinado circuito productivo, siendo los que mayor capacidad de territorialización poseen. 
posición y función en el circuito productivo le da a esta organización un poder importante de negociación y su vinculación con el Estado es una de las más relevantes en la matriz social de la cadena. Como consecuencia esta Cámara forma parte de la mesa directiva de la Corporación Vitivinícola Argentina (COVIAR $\left.{ }^{7}\right)$, órgano ejecutor del PEVI; el Consejo Asesor Profesional del INV; la Cámara de Bodegas de Argentina; la Confederación Empresarial y Profesional de San Juan; el Consejo de Seguimiento Tarifario del Ente Provincial Regulador de Energía (EPRE); los Centros de Desarrollo Vitícola; etc., y; la Agencia Calidad San Juan; etc.

Sus miembros tienen un nivel educativo y socioeconómico mayor que los de las otras organizaciones, de maneraque sus capacidades para elaborar estrategias, procesar los datos o la información de mercado, e incluso los recursos que poseen, son radicalmente diferentes a las del resto. Así lo ilustra su gerente:

Tenés una ventaja ahora que es la comunicación, entre el celular e internet estamos permanente[mente]; es más, con la COVIAR, estamos usando últimamente la video conferencia. Entonces hay muchos viajes que nos estamos evitando, porque la videoconferencia es como si estuviéramos hablando acá, es una pantalla grande y te la dividen en cuatro, si hay cuatro provincias o grupitos entonces la dividen en cuatro y usted ve simultáneamente los cuatro. Cuando compartimos reuniones con el consejo técnico asesor del INV, en vez de viajar a Mendoza tenemos una reunión acá, ahora tenemos una en Mendoza, pero San Rafael, San Juan, Salta, la Rioja, participamos por videoconferencia y te evitas un viaje por una reunión de cuatro horas. Lo que pasa es que es tan difícil la competitividad del mundo y estamos tan

La COVIAR es creada por ley nacional № 25.849/2004, y definida en su artículo 1 como persona jurídica de derecho público no estatal, destinada a gestionar y coordinar la implementación de denominado Plan Estratégico Argentina Vitivinícola 2020 (PEVI). interrelacionados que no es solamente los temas cambiarios sino que todas estas cosas hacen a la industria, entonces eso es lo que le da movilidad a la cámara hoy en día, para que sea efectiva su acción entre los socios.

\subsubsection{Cámara Argentina de Fabricantes y Exportadores de Mosto}

En esta cámara se organizan los agentes concentradores del mosto $^{8}$, radicada en la provincia de Mendoza. Si bien se crea en 1991, su actividad no tiene relevancia hasta 1997 cuando el mosto se consolida como una de las exportaciones más importantes en la estructura productiva. Para asociarse, sus miembros deben reunir dos requisitos: ser concentradores de mosto (no sólo elaboradores) y exportar. Estas dos características revelan el tamaño de estos agentes y la incidencia que pueden llegar a tener, al menos en una provincia como San Juan, en la que el $50 \%$ de su producción es destinada a la elaboración de mosto.

\subsubsection{Agentes paseros}

La actividad pasera resulta un caso interesante, ya que en un mismo sector hay diferentes representaciones según la fracción de clase a la que pertenezca. Existen dos Cámaras, aunque hay pocos agentes. Una de ellas representa los intereses de los agentes exportadores. La otra,representa también a grandes agentes, en términos de volúmenes, pero con mayores

\footnotetext{
La producción de mosto tiene dos etapas. La primera es la de la elaboración de la cual se obtiene el mosto sulfitado, por lo que se requiere tecnología moderna y generalmente es realizada en su conjunto por bodegas elaboradoras a granel de bajo nivel competitivo. La segunda etapa es la de concentración para lo que se necesitan equipos de última generación, es realizada por grandes agentes altamente competitivos vinculados al mercado externo.
} 
dificultades para el acceso a la tecnología o al financiamiento para su adquisición. Éste es el caso de la Cámara de Pasas de Uva y Afines de San Juan, creada en 1973. Tiene una incidencia y participación intermedia en los organismos públicos y/o mixtos que deciden las políticas del sector. Esta organización no participa de las negociaciones paritarias, ni tiene un puesto asignado como Cámara en COVIAR (aunque participó en los foros iniciales), pero está incluida en otros espacios como Calidad San Juan o la corresponsabilidad gremial. Está integrada aproximadamente por 15 empresas que industrializan pasas propias y de terceros. La matriz descrita hasta aquí se resume en la Figura 1:

Figura 1. Principales organizaciones vitivinícolas en San Juan

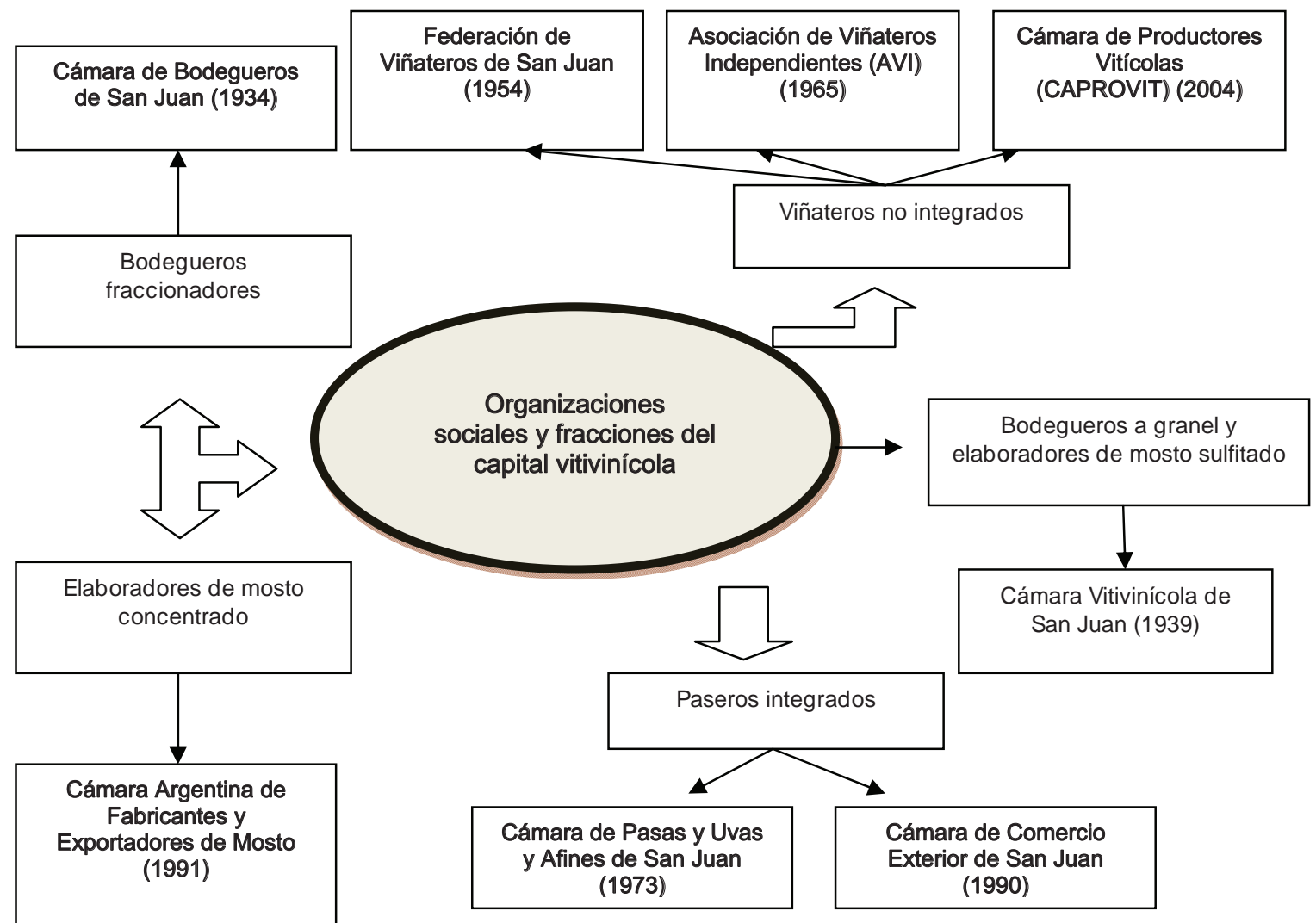

Fuente: elaboración propia. 


\section{Desarrollo y discusión}

Una primera proposición sobre la relación Estado y capital es que a menor nivel de capital y capacidades locales, es menor también el acceso a las políticas públicas. Las organizaciones que agrupan a productores no integrados, caracterizados por el nivel más bajo de capitalización, tienen una escaza representación en las instituciones públicas, a pesar de que son las que mayor cantidad de miembros tienen. Los miembros que las integran tienen, además, un bajo nivel de participación en la apropiación de los ingresos generados en el circuito productivo, y sugerentemente son los de menor acceso a las políticas estatales.

Esto permite una segunda inferencia respecto a la cantidad de los socios, el número de miembros en una organización tiene una relación muy baja con la capacidad de obtener beneficios. La negociación política, la gestión ante los legisladores y tomadores de decisión, los vínculos políticos, las alianzas y entramados tejidos alrededor del poder oficial son más importantes al momento de obtener recursos del Estado. Así, por ejemplo, en los albores de la creación del PEVI, cuando las dos organizaciones históricas -AVI y la FDSJ- se opusieron y la criticaron, fueron rápidamente excluidas de la mesa de decisiones de COVIAR, y su lugar fue ocupado por CAPROVIT, creada con la venia oficial posteriormente a COVIAR. Así, esta institución viabiliza la alianza entre el núcleo del circuito y el Estado, ya que los agentes con mayor capacidad de acumulación necesitan del poder de coacción público para la imposición de normas regulatorias. La alianza entre los intereses ideológicos partidarios y el capital dominante disuelve potenciales movimientos de los grupos subalternos, en este caso a través de la creación de una organización. Por tanto, se infiere una tercera proposición que indica que probablemente las organizaciones que se oponen a la política hegemónica suelen ser invisibilizadas en las relaciones de poder, y por ende, desvinculadas de la política oficial.

Sumado a su resistencia, el análisis no debe excluir los cambios y accesos a los nuevos patrones productivos, de los cuales muchos de los miembros de estas organizaciones están alejados. El avance del paradigma tecnológico de última generación tiene como consecuencia la pérdida de territorialidad de algunos agentes con dificultades importantes para adaptarse a las nuevas exigencias del mercado mundial. En este contexto, las organizaciones que nuclean a productores no integrados o con integración simple pierden territorialidad en el espacio, ejerciéndola aquellas cuyos miembros sí están en condiciones de competitividad global.

Otra característica de las organizaciones más pequeñas en su vinculación con el Estado es que lo hacen a través de mecanismos formales, particularmente mediante el pedido de audiencias e inicio de expedientes. Sin embargo, cuando sus demandas no son atendidas recurren a los piquetes, cortes de ruta, derrame de uva, tractorazos, etc. En general, más que estrategias de expansión, desarrollan estrategias defensivas frente a las políticas estatales que perjudican al sector. Perciben que el Estado avanza continuamente sobre los intereses del sector y despliegan un sinfín de maniobras a los efectos de cooptarlos o neutralizar su acción. Así, por ejemplo, a mediados del 80 se suspende la Obra Social ${ }^{9}$

En Argentina se le denomina obra social a la cobertura de salud de los trabajadores, similar a las Instituciones de Salud Previsional en Chile. 
Provincia (que es administrada por el Estado) a los afiliados de la Federación de Viñateros, liderada por un fuerte opositor del gobierno provincial, habilitándola nuevamente en la década del 90.

De manera inversa, los agentes con mayor poder en el circuito productivo vitivinícola reconocen que no son ellos los que van a solicitar un crédito o un subsidio al Estado. En el mejor de los casos son los funcionarios los que los llaman para negociar algunas condiciones del circuito, como el precio de la uva, e incluso en contiendas electorales, tal como afirma el gerente de la Cámara de Exportadores de Mosto: "Por supuesto cuando hay épocas de elecciones hablamos con los candidatos a gobernador, bueno en San Juan no hace falta, pero acá sí (Mendoza). Por ahí nos llaman o nosotros llamamos. ¿Y cuál es la diferencia respecto a San Juan y a Mendoza? Porque en San Juan siempre gana Gioja ${ }^{10}$, y él nos llama a nosotros. Por eso. En cambio acá no hay reelección y, bueno, cada 4 años hay uno nuevo".

Los líderes de las organizaciones de viñateros no integrados perciben que son negados como interlocutores representativos del sector, y que el gobierno los invisibiliza y deslegitima. Esto se expresa en dos direcciones. Por un lado, no son consultados respecto a las políticas vinculadas al sector. Quedaron excluidos del Plan Estratégico Vitivinícola. No son titulares de una banca en la política que estructura oficialmente toda la actividad. Si bien participaron en el tramo inicial de diseño de la política (foros y validaciones territoriales), durante la implementación fueron críticos de su

Gioja, José Luis, es el gobernador de la provincia de San Juan desde el 2003, cargo para el que fue reelegido en el 2007 por segunda vez y en el 2011 por tercera vez consecutiva. organismo ejecutor, la COVIAR. Los dirigentes viñateros afirman que es una institución puesta al servicio de los grandes agentes vitivinícolas, ya que la mayoría de sus acciones están dirigidas a beneficiar a esa fracción. Por otro lado, no son convocados en las audiencias para resolver los reclamos que ellos mismos inician. Por ejemplo, desde hace años la AVI tiene una política de reclamo sistemático frente a la escasez de agua ${ }^{11}$ y de obras públicas en infraestructura hídrica (arreglo de pozos públicos). En el 2012, en una clara maniobra de neutralización, el gobierno convocó a los miembros de las Juntas de Riego ${ }^{12}$ y excluyó a los miembros de la $\mathrm{AVI}$, siendo que éstos eran los que habían logrado tematizar la cuestión. Así lo afirma un dirigente:

Permanente participamos, si es por el gobierno nos quieren excluir porque no coincidimos con su postura, a veces trata de dividir[nos], por ejemplo, en la manifestación del jueves por el agua recibió a los regantes y no recibió a las entidades que pidieron audiencia con más de 200 firmas, y los recibe sólo a ellos para tratar de desinflar la protesta, quiere tapar la realidad hídrica que ellos mismos han ocasionado, perjudicando muchísimo a los productores y a la población, porque si hubieran puesto en marcha la batería de pozos que nosotros decíamos, hoy tendríamos diques con agua, turismo, generaríamos energía, los productores tendrían más tranquilidad porque hubieran sembrado más cantidad, ¿por qué no lo hicieron? Porque ellos quieren el agua para las mineras ${ }^{13}$

San Juan atraviesa desde el 2010 por una crisis hídrica importante que subsume a cualquier actividad agrícola en problemas productivos derivados de la sequía.

2 El organismo encargado de regular el agua para riego en San Juan se denomina Dirección de Hidráulica, y su dirección está conformada por un Honorable Consejo, una Comisión de Regantes y 18 Juntas de Riego. Éstas son las encargadas de establecer los turnos de riego a efectos de organizar la distribución del agua en cada departamento provincial.

13 Fuente: "Incidentes en una marcha en San Juan". Diario La Nueva Provincia Online (8/03/06). 
Estas prácticas son concebidas como estrategias de represión por parte del gobierno, que "castiga" a los productores por no estar alineados con la política oficial.

Ellos, por su parte, perciben que sus opiniones son ignoradas, así lo aclara un dirigente: "últimamente el Ministerio de Producción nos ignora por opinar diferente, nos margina por ser diferentes"14. En el 2006, la AVI y la Federación de Viñateros reclamaron por el bajo precio de la uva. El presidente de la última organización señalada afirmó: "Nosotros estamos pidiendo la renuncia del ministro de la producción, porque nunca nos recibió y nunca se preocupó de lo que nos está pasando".

Una cuarta conclusión se refiere al nivel de participación en las organizaciones de base. Mientras menor es el nivel de capitalización, menor es el índice de participación. Si bien la caída en la participación se origina en una cultura individualista contemporánea, existe una importante deslegitimación de las estructuras organizacionales, junto con la creencia de que estas organizaciones son impotentes frente a la acción de los grupos concentrados.

La falta de participación es mayor en las organizaciones de viñateros no integrados, lo que abre una brecha entre las bases sociales y los dirigentes. Los bodegueros, en cambio, tienen un índice de participación más alto, porque perciben que las organizaciones son un medio efectivo para la canalización de sus demandas.

Fuente: "Los viñateros se sienten marginados". Diario de Cuyo Online (7/01/11)
A diferencia de las organizaciones que agrupan, las fracciones integradas tienen una posición crítica de la política vitivinícola provincial y regional, y algunas percepciones positivas de la política nacional. La minería ${ }^{15}$, vista como una actividad que compite por los recursos fundamentalmente en lo que respecta al agua, la mano de obra y la rentabilidad-, son las principales críticas al gobernador.

Respecto a los subsidios entregados a los viñateros y sus organizaciones, debe apreciarse que, tal como están diseñados, no tienen un efecto nivelador en el territorio que a largo plazo incremente la apropiación del excedente generado en el circuito. Por el contrario, tienen el objetivo de sostener e, incluso, aumentar la cantidad y la calidad de la materia prima. Se podría presumir que con mayor cantidad de uva los productores también se beneficiarían. No obstante, en una producción no diferenciada, cuya principal estrategia de rentabilidad es la escala combinada con una estructura minifundista y un precio impuesto por el núcleo de acumulación -por tanto siempre bajo-, el aumento subsidiado en la calidad y la cantidad de uva beneficia, en el fondo, a los grandes agentes vitivinícolas con posibilidades de elaborar el vino, o mosto concentrado, fraccionarlo y exportarlo.

Se trata, entonces, de subsidios que están destinados a mejorar la competitividad de algunos, pero no los ingresos de todos, en particular los de los grupos subalternos del circuito, productores tradicionales no integrados y asalariados. Además, el subsidio tiene un efecto positivo indirecto para el

A principios del 2000, San Juan comienza a especializarse en actividades vinculadas a la minería metalífera. 
industrial y es legitimador para el Estado, de modo que su intervención permite armonizar las relaciones inter-capital en el circuito. Así lo ilustra un dirigente industrial cuando afirma:

Esto de PROVIAR ${ }^{16}$ de alguna manera ha ido limando [los conflictos entre productor e industrial] o colaborando para que pasen todas estas cuestiones casi perdurables, que un año el viñatero y el otro año pasa la factura el bodeguero. Digamos la intervención del gobierno, así como es Gioja, a lo campechano, -muchachos juntémonos, veamos, firmemos, comprometámonos, nosotros los ayudamos con créditos, ustedes pongan unos pesos-, así el viñatero está contento, entonces el año que viene va a volver a destinar la uva para mosto y, bueno, y va. $Y$ eso sí que, sin duda, ha colaborado.

De manera inversa a las organizaciones de productores no integrados, las representativas de agentes integrados, en general, tienen una percepción positiva del gobierno provincial y negativa del nacional. La política comercial, incluido el tipo de cambio, son las críticas más importantes. El discurso, a grandes rasgos, plantea que la regulación y el modelo de la Argentina están diseñados principalmente para los agentes de la Pampa Húmeda, lejos de los intereses de las economías regionales.

A nivel provincial, la percepción de los agentes integrados respecto del Estado es mayoritariamente positiva, ciertamente, mientras más cerca está el ejecutivo del agente

PROVIAR es un proyecto de Integración de Pequeños Productores a la Cadena Vitivinícola que se implementa en el marco del Plan Estratégico Vitivinícola, que tiene como objetivo formal mejorar la rentabilidad y la estabilidad de los ingresos de los pequeños productores que participan en la cadena vitivinícola. económico, más favorable es la apreciación de este respecto de la gestión pública. En departamentos alejados del Gran San Juan, los viñateros no integrados se sienten más representados por sus intendentes que por la política provincial o la nacional, incluso en áreas que escapan a la dinámica productiva misma. Evidentemente, se concluye que el vínculo es más fuerte y está condicionado por la cercanía de las relaciones, aunque ese productor nunca haya sido beneficiario de una política estatal. En este marco, el Estado nacional no logra capitalizar políticamente sus acciones destinadas a favorecer a las fracciones más pequeñas. Paradójicamente, grupos de productores beneficiados con PROVIAR (programa financiado con un crédito del BID, avalado y pagado por el Estado nacional) son fuertemente reaccionarios frente a la política nacional. Aunque resulte incongruente, esta fracción critica las retenciones a las exportaciones o las demoras en los reintegros, y son un grupo que en su mayoría no exporta, reprueba el tipo de cambio cuando sus ingresos y gastos son en pesos, o censura el valor de los costos laborales cuando es la fracción que menos cantidad de trabajadores necesita, por ejemplo.

Por tanto, lo que se infiere de lo dicho anteriormente es que en sistemas de gobierno federales como es el caso de Argentina, los gobiernos locales tienen mayor nivel de legitimidad para las organizaciones que nuclean a agentes medianos tradicionales, a pesar de que la mayoría de las políticas con las que fueron beneficiados son financiadas con fondos nacionales. Siguiendo con el rol del Estado, se registró que mientras más pequeño y vulnerable es el sector que representa la organización, mayor es la demanda de 
intervención del Estado. De manera inversa, mientras mayor es el tamaño del capital de los agentes representados, la demanda de políticas públicas es menor e, incluso, la intervención estatal llega a ser molesta. De este modo, la percepción sobre el rol que debería tener el Estado divide nuevamente a organizaciones que representan a productores integrados y a los que no lo están. Los viñateros más pequeños no integrados reclaman la presencia del Estado, demandan una intervención activa de los funcionarios, y los industriales insisten en que interviene demás, sobre todo en los últimos años.

Por otro lado, las organizaciones de productores no integrados tienen un mayor espacio de participación en entidades nacionales como el INV, el INTA, el EPRE, UNSJ, Secretaria de Agricultura Familiar, que en las provinciales o regionales, como la Agencia Calidad San Juan - la mesa directiva de la COVIAR, de la que quedaron afuera la Federación de Viñateros y la AVI. El INTA es la institución de gobierno con mayor legitimidad, y tiene una percepción positiva en todas las fracciones de la cadena.

Todas las organizaciones tienen en común que en el proceso de toma de decisiones y resolución de conflictos prima el consenso y la legitimidad frente a los mecanismos institucionales estatuidos. Otro de los aspectos en común es que ninguna de las organizaciones tiene como política formal el apoyo de un candidato en las elecciones (como pasó en otras provincias).

Por su parte, una quinta conclusión se refiere a que mientras mayor es la importancia económica o financiera de una actividad productiva en el territorio, mayor es la incidencia de sus organizaciones representativas en la configuración de las características dominantes en el territorio. El ejemplo del mosto en los últimos años es clave. En efecto, si bien la Cámara del Mosto se crea en 1991, es recién a fines de esa década que adquiere relevancia territorial en el entramado socioproductivo. Esta Cámara, que sólo agrupa a los agentes concentradores y exportadores de mosto, se torna importante especialmente en 1997, cuando el mosto cobra relevancia en la estructura productiva de San Juan. En ese año se exportaron 123.976 toneladas de mosto concentrado, según datos del INV, alcanzando un récord respecto a los valores exportados en 1992 (38.777), que es superado recién en el 2006 con 136.523 toneladas. En años anteriores a 1997, cuando el tipo de cambio no fue conveniente para las exportaciones y éstas registraban un bajo volumen de envíos, esta organización tuvo un rol secundario.

De esta forma, si en la importancia de las organizaciones incide la actividad productiva, el Estado también cumple un rol esencial, ya que a través de sus políticas estatales promueve -o no- el crecimiento de determinadas actividades. En otras palabras, años de venta, expansión y acumulación ampliada son sostenidos por un conjunto de regulaciones particulares, manteniendo la armonía y la legitimación de dichas fracciones, y relegando -0 no- a las organizaciones que las representan. De este modo, se va tejiendo un entramado entre capital económico y poder político que va construyendo el perfil de desarrollo del territorio, en una dinámica en la que no sólo el Estado configura, sino que los agentes también inciden, de manera directa e indirecta, como relaciones de fuerza en sus políticas. Así, por su importancia cada vez mayor en los últimos años, la Cámara de Mostos participa 
en la regulación del valor pagado cada año por gamela ${ }^{17}$, y tiene una influencia importante en la configuración de las condiciones del circuito: en San Juan, por ejemplo, son los agentes con los que se negocia el precio de la uva en cada vendimia. Así como en la década pasada las bodegas a granel tenían un rol predominante en la imposición del valor y las condiciones de pago de la uva a los viñateros, en la actualidad los mosteros son los que tienen ese rol. Las cámaras bodegueras son reemplazadas por la Cámara del Mosto para establecer el valor del precio de la materia prima del circuito.

Por último, el núcleo de acumulación del circuito productivo vitivinícola integrado por los agentes más grandes en términos de capital no participan de ninguna organización sectorial, sus luchas son llevadas a cabo fundamentalmente de manera individual. Los tres representantes del núcleo de acumulación, Baggio, FECOVITA y Peñaflor (que concentra el $8 \%$ del mosto total exportado por la Argentina en el 2012), no están agrupados en ninguna organización sectorial. El poder que conservan en el circuito para configurar e imponer las condiciones es tal, que estos agentes no necesitan agruparse en ninguna cámara, organización o federación que defienda sus intereses. El acceso al poder se configura por otros canales no institucionalizados, su territorialidad es tan poderosa que se imponen a través de otros medios, valiéndose principalmente de su posición privilegiada en el mercado, y de la influencia directa con el gobierno de turno, por lo que se concluye que el tamaño del capital no tiene incidencia en la

Aunque no fue parte en los convenios colectivos originales que rigen a los trabajadores de viña (154/91) y de bodega (85/89), ya que su importancia como sector era mínima. organización colectiva. Estas vinculaciones se ilustran de mejor manera en la Figura 2.

\section{Conclusiones}

Las organizaciones de mayor incidencia en el territorio, entendido como un espacio de relaciones de poder, son las que representan a los agentes integrados y con un mayor nivel de capitalización. Por el contrario, las organizaciones de menos influencia a nivel territorial son las que representan a los agentes no integrados de las fracciones más pequeñas del capital.

Las organizaciones dominantes de agentes integrados inciden en la transformación del territorio a través de la influencia directa en los tomadores de decisiones públicas, como, por ejemplo, el establecimiento del precio de la uva o el valor de la gamela pagado a un obrero temporal decidido en paritarias o consejos sectoriales. Otra de las formas de incidencia indirecta es por medio de campañas de movilización social, como, por ejemplo, la declaración del vino como bebida nacional, sancionada por ley nacional $\mathrm{N}^{\circ}$ 26.870/13 y promovida por COVIAR, de cuyas filas están excluidas las organizaciones que representan a los agentes más pequeños. Por último, la formación de alianzas para la instalación de agendas específicas y la participación en espacios oficiales de decisión, como, por el ejemplo, en el INV o en COVIAR, también se presentaron como mecanismos de influencia en la arena territorial.

Las transformaciones territoriales más importantes llevadas a cabo particularmente en el sector vitivinícola de la Provincia de San Juan, y que impulsan nuevos patrones de 
Figura 2. Relación entre el Estado y las organizaciones según el tamaño de la fracción del capital

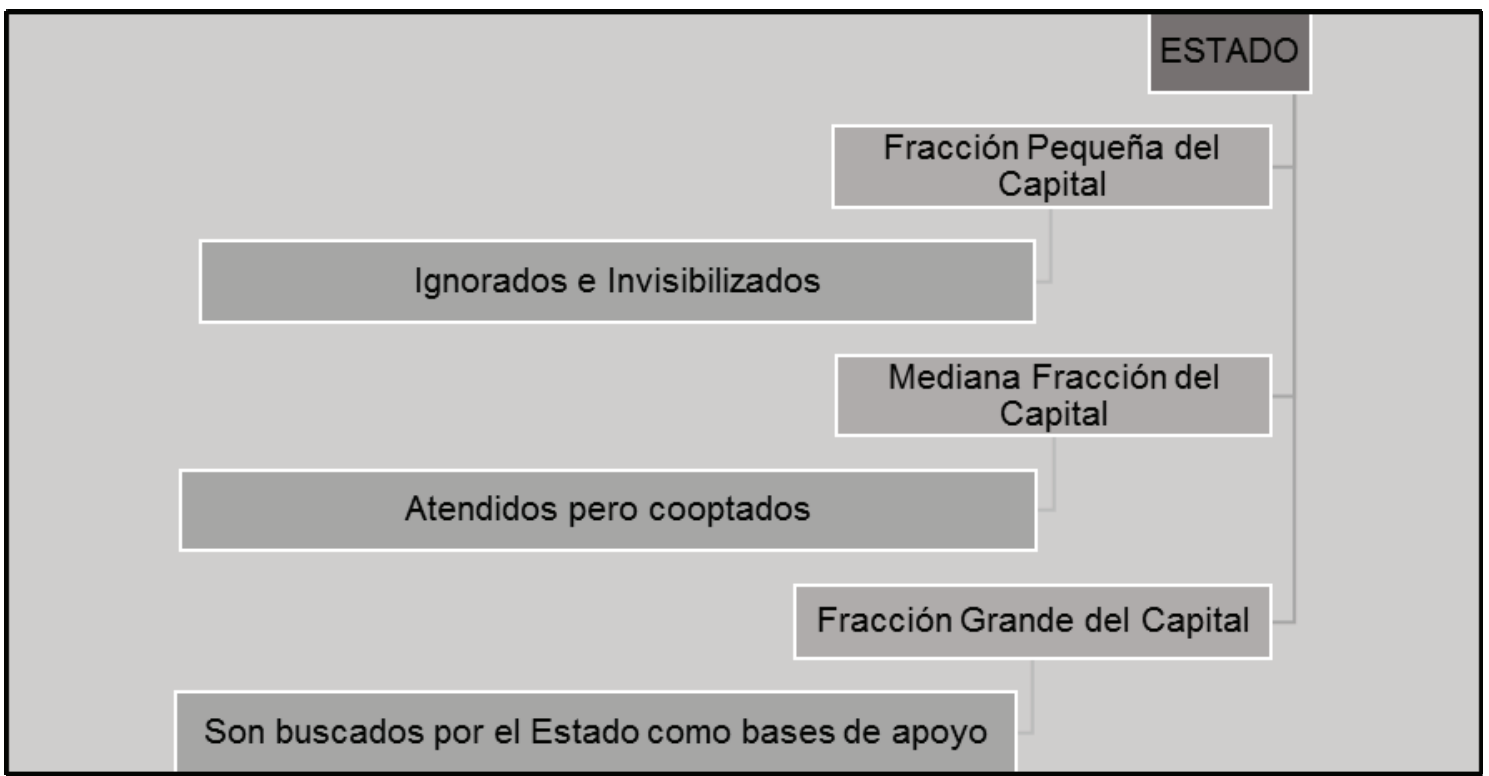

Fuente: elaboración propia.

competitividad tales como el crecimiento de la superficie implantada, la diversificación de la matriz productiva con la incorporación de nuevas variedades, la incorporación de nuevas tecnologías de producción y fraccionamiento, la incorporación de nuevos capitales e, incluso, la expulsión de los productores pequeños tradicionales, son promovidas fundamentalmente por agentes que pertenecen a organizaciones representativas de la fracción dominante.

Las organizaciones que menor legitimidad política y representación tienen en el territorio son las menos capitalizadas, aunque su número de miembros sea significativamente mayor que el resto. Así, características de los socios como la propiedad del capital, la integración en la cadena, la inserción en el mercado, el uso de tecnología de última generación y otras variables relativas a la competitividad, son determinantes en el logro de objetivos e incidencia en las relaciones de poder de una organización.

En el ejercicio de la territorialidad es clave la conformación de alianzas, la consolidación de capital social, y las negociaciones de una organización influyente. Por el contrario, las que no tienen estas características pierden territorialidad, quedan invisibilizadas en las relaciones de poder, y excluidas de las políticas públicas más importantes.

Las organizaciones que representan a agentes de capital más pequeño despliegan estrategias defensivas, mientras que las más grandes despliegan estrategias de expansión y 
apropiación del espacio público. En el caso de estas últimas, la influencia es mayor cuando la actividad económica que representan destina ingresos importantes a las arcas del Estado.

Algunas organizaciones perdieron poder en el territorio pero conservaron cierto capital simbólico (bodegueros trasladistas), suficiente para legitimar el discurso del gobierno provincial. La armonía entre este sector y los funcionarios evita un conflicto inter-capital (industrialagrícola), y la reproducción sistemática de las relaciones de poder al interior del circuito productivo.

Los gobiernos locales o municipales tienen mayor nivel de legitimidad entre las organizaciones que el nivel nacional, el cual no logra capitalizarse políticamente a pesar de ser el principal origen de los fondos destinados al sector.

Algunos de los agentes más poderosos del núcleo de acumulación no pertenecen a ninguna organización ni necesitan una estructura colectiva, pues su poder es tal que despliegan sus estrategias de manera individual e, incluso, tienen mayor relevancia al momento de imponer temas en la agenda que organizaciones de casi mil miembros, pero que pertenecen a la fracción pequeña del capital.
La creación de nuevas organizaciones es una estrategia de los funcionarios públicos, cuando las que existen no son funcionales a los intereses de los funcionarios de turno. Un ejemplo de ello es la creación de CAPROVIT.

Por último, se concluye además que, probablemente, a la luz de las pujas intracapital al interior de un determinado circuito productivo y de la heterogeneidad en la matriz social, en términos organizacionales el sector no registra capacidad para organizarse como un sujeto político con miras a la transformación territorial.

En este contexto, la vitivinicultura, que fuera la actividad histórica que configuró las principales relaciones de fuerza en la provincia, pierde hegemonía frente a la minería extractiva exportable, una producción que compite en el uso de los recursos. Las luchas se realizan por fracciones y en algunos casos de manera individual. La acción colectiva sectorial no es característica en la vinculación con el Estado $\mathrm{y}$, por tanto, la defensa del sector no encuentra sujetos políticos con voluntad suficiente en el territorio, sino sólo agentes que no renuncian a la defensa de sus intereses particulares, incapaces de organizar un histórico bloque social de fuerzas.

\section{Bibliografía}

Arqueros, M. 2007. "Territorio y tramas locales en San Carlos, Salta". Territorios en construcción. Actores, tramas y gobiernos: Entre la cooperación y el conflicto. Manzanal, M., Arzeno, M. y Nussbaumer, B. (Comps.). Buenos Aires: Ciccus. 135-166.

González Bombal, I. 2003. "Capítulo de presentación”. Organizaciones de la sociedad civil e incidencia en políticas públicas. González Bombal, I. y Villar, R. (Comps.). Buenos Aires: Libros del Zorzal. 9-12.

Madoery, O. 2009. "Un análisis de caso desde la perspectiva del desarrollo territorial. Rosario, Argentina, 1995-2008". Semestre Económico 12 (24): 69-92.

Manzanal, M. 2006. "Regiones, territorios e institucionalidad del desarrollo rural". Desarrollo rural. 
Organizaciones, instituciones y territorio. Manzanal, M., Neiman, G. y Lattuada, M. (Comps.). Buenos Aires: Ciccus. 21-50.

Moscovich, L. 2008. "Estado y sociedad civil en el Gran Buenos Aires. Cambio y tensiones en las nuevas relaciones de gobierno local". La economía política de la pobreza. Cimadamore, A. (Comp.). Buenos Aires: CLACSO. 261-296.

Oszlak, O. y O'Donnell, G. 1976. Estado y políticas estatales: Hacia una estrategia de investigación. Alcalá de Henares: INAP.

Schlemenson, A. 1993. Análisis organizacional y empresa unipersonal. Crisis y conflicto en contextos turbulentos. Buenos Aires: Paidós.

Schvarstein, L. 1992. Psicología social de las organizaciones. Nuevos aportes. Buenos Aires: Paidós.

Subirats, J. y Gomá, R. 1998. "Políticas públicas: Hacia la renovación del instrumental". Planificación y evaluación de políticas de información. Subirats, J. y Gomá, R. (Orgs.). Barcelona: Ariel. 21-36.

Thwaites Rey, M. 1999. El Estado: Notas sobre su(s) significado(s). Mar del Plata: Universidad Nacional de Mar del Plata-FAUD. 
